$\mathrm{Y}-12$

\section{OAK RIDGE \\ $Y-12$ \\ PLANT}

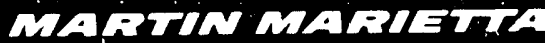

CHOOSING AND IMPLEMENTING A COMPUTER SYSTEM FOR PLANT LUBRICATION: NINE STEPS TO SUCCESS 
This report has been reproduced directly from the best available copy.

Available to DOE and DOE contractors from the Office of Scientific and Technical Information, P. O. Box 62, Oak Ridge, TN 37831; prices available from (615) 576-8401, FTS 626-8401.

Available to the public from the National Technical Information Service, U. S. Department of Commerce, 5285 Port Royal Rd., Springfield, VA 22161.

This report was prepared as an account of work spunsored by an agency of the United States Government. Neither the United States Government nor any agency thereof, nor any of their emp!oyees, makes any warranty, express or implied, or assumes any legal liability or responsibility for the accuracy, completeness, or usefulness of any information, apparatus, product, or process disclosed, or represents that its use would not infringe privately owned rights. Reference herein to any specific commercial product, process, or service by trade name, trademark, manufacturer, or otherwise, does not necessarily constitute or imply its endorsement, recommendation, or favoring by the United States Government or any agency thereof. The views and opinions of authors expressed herein do not necessarily state or reflect those of the United States Government or any agency thereof. 


\title{
CHOOSING AND IMPLEMENTING A COMPUTER SYSTEM FOR PLANT LUBRICATION : NINE STEPS TO SUCCESS
}

\author{
J.C. Nook
}

April 3, 1991

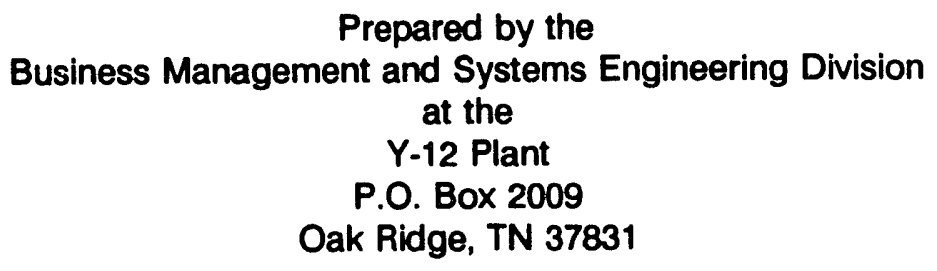

Managad by

Martin Marietta Energy Systems, Inc.

for the

U.S. DEPARTMENT OF ENERGY

under Contract No. DE-AC05-84OR21400

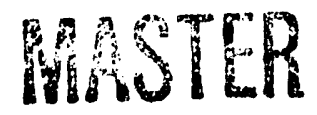

DISTRIBUTION OF THIS UOCURENT IS UN!!MITED 


\title{
CHOOSING AND IMPLEMENTING A COMPUTER SYSTEM FOR PLANT LUBRICATION : NINE STEPS TO SUCCESS
}

\author{
Presentation Abstract
}

Rapid advances in computer software offer many opportunities for increasing efficiency and productivity; however, choosing the right software package and achieving its full potential can be a challenging task. Lubrication engineers faced with the selection and implementation of a computer system will find that they can increase their chance of success when they follow the nine steps outlined in this paper. These steps provide a solid framework for managing the project through its full life-cycle from initial conception until final retirement of the system. Lubrication Departments that already have computer systems in place can also benefit from these steps by picking up at the corresponding point in the systern's life and following the remaining steps. 


\section{CHOOSING AND IMPLEMENTING A COMPUTER SYSTEM FOR PLANT LUBRICATION : NINE STEPS TO SUCCESS}

As engineers and managers we are constantly reminded that this is the era of computerization. Rapid advances in computer software offer many opportunities for increasing efficiency and productivity. However, choosing the right software package and achieving its full potential can be a challenging task. All too often, companies spend money on computer software and are then disappointed when they find that it fails to provide the anticipated benefits or that it sits on the shelf and is never used.

The lubrication organization has a vital interest in the success of a computer system. It is the organization that will be using the system on a day-to-day basis, will be charged with making it work, and will be held accountable for achieving the desired cost savings and benefits. Yet in many cases, representatives of the organization are left out of project teams formed to choose and implement computer systems because it is assumed that anything related to computers should be handled by the data processing group. The intent of this paper is to help lubrication engineers to better understand the computer software development process so that they can effectively manage and actively participate in a software project. The lubrication engineer's leadership and job knowledge are key to a software project and will greatly increase its chances for success.

\section{LIFE-CYCLE PHASES}

The life-cycle of computer software can be broken into three distinct phases, each containing three steps. These nine steps organize computer software development into a logical process designed to assure that all necessary requirements are met to assure success. Each step is of a size and scope that allows it to be planned and managed successfully. Predetermined milestones and deliverables are identified for 
each step. This planning allows the project leader to measure progress and obtain appropriate management understanding arid approval before proceeding to the next step. An additional benefit is that the process allows cost commitments remain low during the early phases when uncertainties are greater. Additional resources are committed only as the project matures.

The nine steps provide a solid framework for managing the project through its full life-cycle from initial conception until final retirement of the system. Yet they are flexible. They can be tailored to suit the needs of organizations ranging from small companies to major corporations and for projects of varying complexities from the purchase of a small program to run on a personal computer to the development of a major mainframe system.

\section{PHASE ONE - SYSTEM DEFINITION}

The first phase in the life of the software development process is System Definition. During this time an idea for a software application progresses from conception into a clear definition of what that application is to accomplish. The System Definition Phase contains the first three steps of the project.

- Project Initiation

- Feasibility Study

- Requirements Definition

This phase of the life-cycle relies heavily on information that must come from the lubrication organization. Consequently the Lubrication Engineer will play a major role in this part of the effort. 


\section{Step 1 - Project Initiation}

The project begins when someone recognizes an opportunity for using computer software to increase efficiency or to solve a problem. It may only be a broad idea or concept at first, but during the project initiation step, the objectives and scope are developed in enough detail to set the project in motion and to gain management support and funding. At the conclusion of the this step, the project leader will be able to write a proposal or generate a charter letter that defines the project, identifies the team members, establishes a source of funding, and provides a basic time schedule.

\section{Step 2 - Feasibility Study}

The feasibility study constitutes the next step in the project. Existing practices and current problems are studied in only enough detail to identify alternative solutions and to estimate the benefits and evaluate the risks associated with each alternative. The intent of this step is not to recommend or justify a final solution, but only to uncover more than one alternative and to avoid the possibility of settling on a solution too soon.

The search for feasible solutions will often include a market survey to determine what software and hardware options are available and to gain a general idea of costs and capabilities. If in-house programming capabilities are available, the project should be reviewed with the systems organization for their comments and recommendations relative to developing the in-house product. And though often overlooked, non-computer solutions such as manual systems and administrative controls should also be considered as a part of the study.

Information gathered in the feasibility study is evaluated to determine if a computer system solution is feasible, to generate a preliminary economic analysis and to conclude whether or not the project should be continued. As a conclusion, the study 
findings should be documented for future reference and the results should be presented to sponsoring management.

\section{Step 3 - Requirements Definition}

Requirements Definition is the next step in the development process. This is a major activity in the overall project that develops a clear understanding of what functions are to be accomplished by the new system. The emphasis at this point is on function, that is, "what" the system is to do, not "how" it is to do it. Any tendency to rush into designing the system must be resisted. The design activities will come in a later step.

The detail of the information that is collected in the Requirements Definition step will depend upon the magnitude and complexity of the overall project, but it will generally include the following items:

1.) description of the current computer system if one is being upgraded or replaced or the current manual system.

2.) description of the major functions that the new system must provide

3.) description of data information that is used or exchanged

4.) documentation of any business rules and regulations that must be incorporated into the system

5.) examples of existing forms and reports

6.) specification of system performance criteria

7.) list of current $\varepsilon_{;}$planned hardware components that must be used with the system

8.) identification of any external systems that might require system interaction

9.) statement of any security or audit requirements 
10.) description of testing criteria that will be used in accepting the new system

Information collected in the Requirements Definition step will serve as a specification for the new application. It may be used as part of a bid package if the software is to be procured from an outside source or be given to the in-house programming staff for their use in developing the new application.

\section{PHASE TWO - SYSTEM DESIGN}

The second phase of the software development process is System Design. During this phase the system definition information is turned into an actual software application. The System Design Phase contains the next three steps of the project.

- Functional System Design

- Computer System Design

- Programming and Implementation

This portion of the life-cycle is made up of activities that require technical computer skills; consequently, the major effort will shift from the Lubrication Engineer to a computer analyst.

It should be noted that when existing commercial software is purchased, the activities associated with this phase will have already been competed by the vendor based on generic requirements information.

\section{Step 4 - Functional System Design}

In the Functional System Design step, the computer analyst converts the Requirements Definition information into a description of what the proposed system will look like and how it will work. The completed Functional Design document will include 
a description of the proposed system, information about any interfaces with other systems, and examples of screens and reports that the new application will generate.

The functional design document serves as a proposal that is reviewed with the end-user to assure a mutual expectation as to what the final application will do and to gain approval for continuing the development effort.

\section{Step 5 - Computer System Design}

The next step may be almost invisible to the end-user; yet it is an important part of the total development effort for it is in this step that "what" the system is to do gets transformed into "how" the system will do it. In the Computer System Design step, computer analysts continue the refining and developing process by translating the user specifications and the comments received during the Functional Design step into a set of technical, computer-oriented specifications. These specifications will provide the computer programmers with the detail necessary to plan and execute the actual coding of the program.

\section{Step 6 - Frogramming And Implementation}

As the name implies, the objective of the Programming And Implementation step is to code, test, document, and install the new application. Writing the computer code is the primary activity in this step; however, the preparation of supporting documentation must also take place at this time. A user's guide must be written, training manuals developed, and system documentation generated. The supporting documentation will be vital to a successful start-up of the new application and contribute to long term success. The supporting documentation must be given appropriate attention and not treated as an after thought. 


\section{PHASE THREE - IMPLEMENTATION AND CONTROL}

The third and final phase of the software development process is the Implementation and Control Phase. This phase begins when the software is turned over to the lubrication organization and continues on until it is finally taken out of service. The significance of this portion of the life-cycle phase is often overlooked, but the activities associated with it are quite important and can provide significant dividends for many years into the life of the application. The Implementation and Control Phase contains the three final steps of the project.

- Verification And Acceptance

- Configuration Control

- Post-Implementation Review

Responsibility for this portion of the life-cycle now comes back to the Lubrication Engineer.

\section{Step 7 - Verification And Acceptance}

The objective of the Verification And Acceptance is to assure that the system meets design requirements and to place the new application into use. Once the software has been installed on the computer, the acceptance test that was developed during the System Definition Phase should be conduced to assure that the system meets the design requirements. Any non-compliance must be resolved before acceptance of the system is authorized.

User training sessions should be conducted at this timie. How this is handled will vary greatly, depending upon the complexity of the system and upon company policies and resources. The training may be provide by the software vendor or it might be handled by in-house training personnel. It may be done prior to the actual start-up of the system or it may be part of the initial implementation effort. Careful planning and 
coordination in necessary to assure that the training effort is successful. Problems and frustrations experienced by users during the first few weeks and months of the implementation will bias the user's opinion about the product, will require a long time to correct and may prevent the sysiem from ever being fully accepted.

The start-up plan should be put into place at this time. The detail and complexity of this activity will depend upon the degree of risk associated with start-up of the system. Possible options include:

1.) Begin using the new system and eliminate any existing systems.

2.) Operate the new system in parallel with the existing system for a period of time with planned elimination of the existing system.

3.) Begin using the new system in only one portion of the total operation with planned phasing to full implementation.

Once these activities have been completed, the system is ready to be put into full use.

\section{Step 8 - Configuration Control}

The Configuration Control step serves to maintain the application in a controlled environment that will prohibit any unauthorized changes to the software. A system manager should be designated and that manager should have full responsibility and authority for the system. Any changes to the computer code or the hardware configuration must be thoroughly considered and then adequately tested and documented before being authorized. The system manager will also have authority in determining who will have access to the system, how long data will be archived, and other system management questions.

Configuration control continues until the system is retired. 


\section{Step 9 - Post-Implementation Review}

After the application has been use: for a period of time, the software project team should be reconver.ed for the final step in the process, the post-implementation review. In this step, the team assesses the extend to which the application software meets the original project objectives, reviews any problems that are being experienced and evaluates the development process. Lessons learned from the project will be valuable to the team members and others in the organization when the next software development prốject is initiated.

\section{SUMMARY}

The nine steps outlined in this paper fit together to provide a full picture. If you are responsible for choosing and implementing a computer system, consider this picture. Decide how each step should 'se structured to fit your specific needs. Plan your activities and work confidently toward success. 
Internal Distribution

J.C. Nook (4), 9113/MS 8206

A.E. Stephens, 9103/MS 8140

J.E. Keyes/DOE-OSTI (4)

Y-12 Central Files 

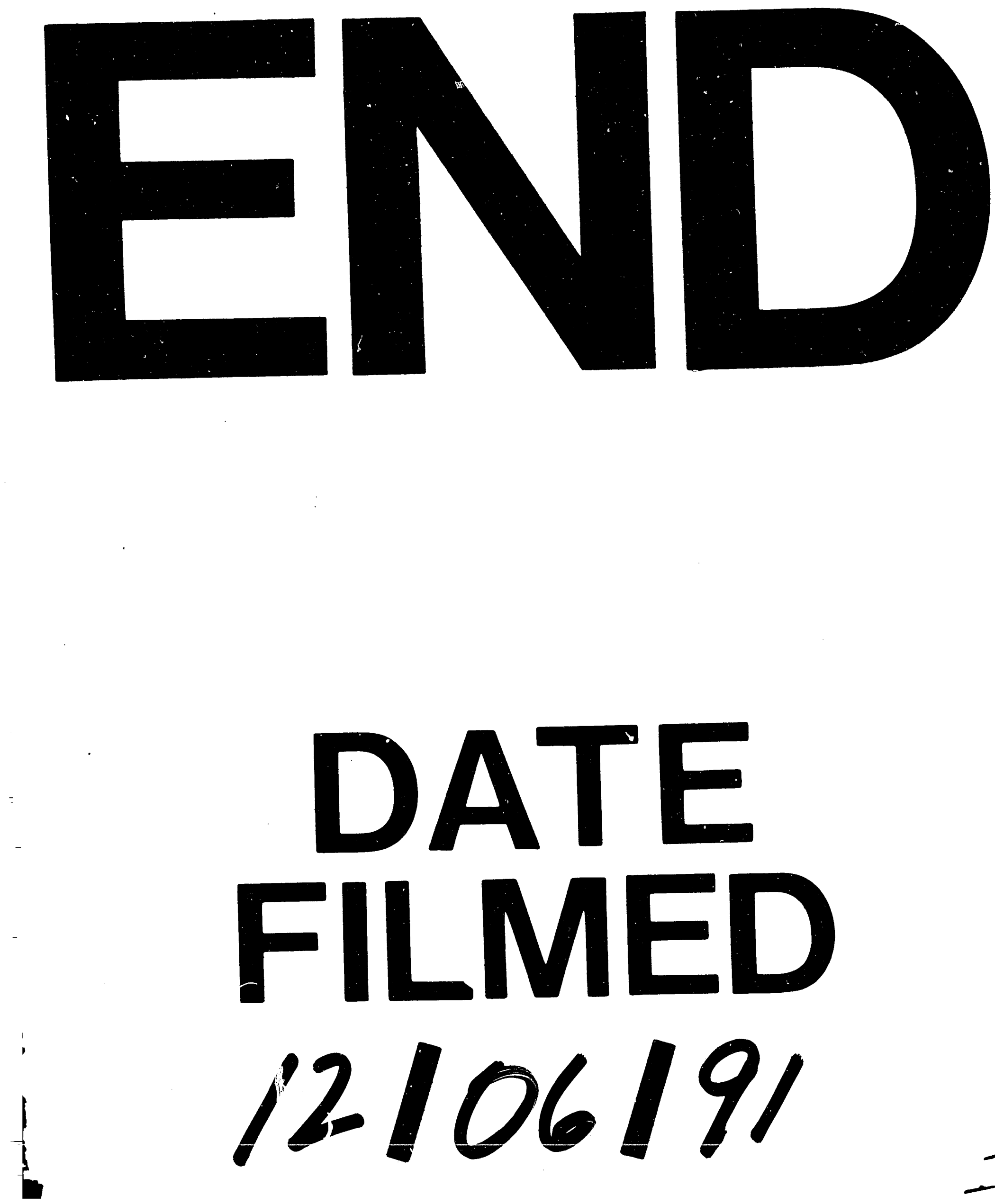
